\title{
Myocardial membrane injury in pediatric cardiac surgery: An animal model
}

\author{
Jonathan R. Egan, MBBS, FRACP, FJFICM, ${ }^{\mathrm{a}, \mathrm{b}}$ Tanya L. Butler, PhD, ${ }^{\mathrm{a}, \mathrm{b}}$ Andrew D. Cole, BAppSc, ${ }^{\mathrm{a}}$ Smartin Abraham, MCh, ${ }^{\mathrm{a}}$

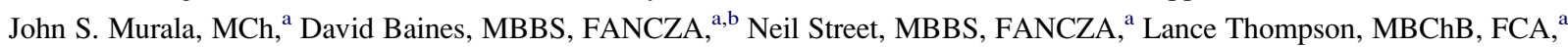 \\ Oliver Biecker, BSc, ${ }^{\text {a John Dittmer, CCP, }}$, Sandra Cooper, PhD, ${ }^{\mathrm{a}, \mathrm{c}}$ Carol G. Au, BSc, ${ }^{\text {, b }}$ Kathryn N. North, MD, ${ }^{\mathrm{b}, \mathrm{c}}$ and \\ David S. Winlaw, MD, FRACS ${ }^{\mathrm{a}, \mathrm{b}}$
}

\begin{abstract}
Objective: Reduced myocardial performance invariably follows pediatric cardiac surgery and is manifested by a low cardiac output state in its severest form. The role of myocardial membrane proteins in this setting is unknown. Dystrophin and dysferlin are involved in membrane integrity, whereas aquaporins selectively transport water. These proteins were examined in a model of pediatric cardiac surgery, together with a trial of poloxamer 188 , which may reduce membrane injury.
\end{abstract}

\begin{abstract}
Methods: Eight lambs were randomized to saline with or without poloxamer 188. Lambs underwent 2 hours of cardiopulmonary bypass and aortic crossclamping. After a further 9 hours of monitoring, the hearts were assessed for water content, capillary leak, and protein expression.
\end{abstract}

\begin{abstract}
Results: Dystrophin expression was unaffected by ischemia/reperfusion, but dysferlin expression was reduced. Aquaporin 1 protein increased after ischemia/reperfusion. Poloxamer 188 administration was associated with supranormal levels of dystrophin, preservation of dysferlin expression, and normalization of aquaporin 1 expression. Poloxamer 188 was associated with less capillary leak, maintained colloid osmotic pressure, and less hemodilution. Poloxamer 188 was associated with an improved hemodynamic profile (higher blood pressure, higher venous saturation, and lower lactate), although the heart rate tended to be higher.
\end{abstract}

Conclusions: Changes in protein expression within the myocardial membrane were found in a clinically relevant model of pediatric cardiac surgery. Indicators of reduced performance, such as lower blood pressure and lower oxygen delivery, were lessened in association with the administration of the membrane protecting poloxamer 188. Poloxamer 188 was also associated with potentially beneficial changes in membrane protein expression, reduced capillary leakage, and less hemodilution.

Reduced myocardial performance may complicate repair of congenital cardiac disease. It occurs to varying degrees, with the most severe form being the low cardiac output state (LCOS). It manifests with reduced perfusion and oxygen delivery-tachycardia, systemic hypotension, oliguria, and cool peripheries. Up to $25 \%$ of patients have a moderate to severe form necessitating optimization of inodilation or institution of mechanical support. Onset usually occurs 6 to 12 hours postoperatively, and it causes the majority of morbidity and mortality in the current era. Although the impact of LCOS is lessened by early supportive measures, such as milrinone, its precise etiology remains somewhat elu-

\footnotetext{
From Kids Heart Research, The Children's Hospital at Westmead, ${ }^{\mathrm{a}}$ the Discipline of Pediatrics and Child Health, Faculty of Medicine, University of Sydney, ${ }^{\mathrm{b}}$ and the Institute for Neuromuscular Research, The Children's Hospital at Westmead, Sydney, Australia.

J.R.E. was supported by an NHMRC Biomedical Research Scholarship (297113), C.G.A. is supported by an NHMRC Dora Lush Scholarship (358800), and D.S.W. is a National Heart Foundation of Australia Career Development Fellow.

Received for publication June 19, 2008; revisions received Sept 1, 2008; accepted for publication Oct 9, 2008.

Address for reprints: A/Prof David S. Winlaw, Paediatric Cardiac Surgeon, Head, Kids Heart Research, Locked Bag 4001, Westmead NSW 2145, Australia. (E-mail: davidw@chw.edu.au).

J Thorac Cardiovasc Surg 2009;137:1154-62

$0022-5223 / \$ 36.00$

Copyright (c) 2009 by The American Association for Thoracic Surgery doi:10.1016/j.jtcvs.2008.10.009
}

sive. ${ }^{1}$ A myriad of intraoperative events contribute. There is direct operative myocardial trauma, a systemic inflammatory response to the artificial surfaces of the extracorporeal cardiopulmonary bypass (CPB) circuit, and ischemia/reperfusion (I/R) injury. Myocardial stunning, hypocontractility despite normal perfusion, results from I/R injury and involves a degree of myocardial edema and capillary leak within the heart, ${ }^{2}$ but edema and dysfunction may not be causally associated. ${ }^{3}$ Hemodilution, however, has been associated with LCOS, with reduced myocardial oxygen delivery and an early increase in lactate after CPB. ${ }^{4}$ Contractile failure has also been demonstrated, ${ }^{5}$ together with apoptosis $^{6}$ and a loss of key contractile elements. ${ }^{2}$ The effect of $\mathrm{I} / \mathrm{R}$ on membrane proteins that surround the contractile proteins are essentially unknown in the clinical situation. Membrane proteins are fundamentally involved in maintenance of normal cellular structure and function, and proteins such as dystrophin and dysferlin have been shown to play key roles in mechanotransduction ${ }^{7}$ and membrane repair in other settings. ${ }^{8}$ Aquaporins (AQPs), present in endothelial cells and the sarcolemma of cardiomyocytes, ${ }^{9}$ are fundamental to water handling and involved in development and resolution of edema in other organs. ${ }^{10}$ Potentially, these membrane proteins may be affected by $\mathrm{CPB}$ and $\mathrm{I} / \mathrm{R}$ and have a role in the pathophysiology of LCOS. 


$$
\begin{aligned}
& \text { Abbreviations and Acronyms } \\
& \text { AQP }=\text { aquaporin } \\
& \text { CPB }=\text { cardiopulmonary bypass } \\
& \text { I/R }=\text { ischemia/reperfusion } \\
& \text { LCOS }=\text { low cardiac output state } \\
& \text { P188 }=\text { poloxamer } 188 \\
& \text { PBS }=\text { phosphate-buffered saline }
\end{aligned}
$$

Dystrophin is a large protein intrinsic to the integrity of the myocardial cellular structure, linking intracellular and extracellular components. The structural role of dystrophin in cardiac muscle is to stabilize the cell membrane while relating the extracellular matrix to the contractile apparatus. The loss of dystrophin from the membrane component of myocardium has been associated with dysfunction. Loss of dystrophin can lead to loss of contractile strength and impaired membrane integrity, leading to cell death. ${ }^{11}$

Dystrophinopathy or impaired dystrophin function has not been investigated in the post-CPB setting. A dystrophinopathy has been described in a number of settings somewhat analogous to the postoperative LCOS settings, albeit more severe, such as end-stage ischemic cardiomyopathy, ${ }^{12}$ Coxsackie B myocarditis, ${ }^{13}$ and animal models of coronary occlusion. ${ }^{14,15}$ Potential analogies between LCOS and an ischemia-induced dystrophinopathy are supported by protection against loss of dystrophin and maintenance of function with ischemic preconditioning. ${ }^{14}$ We explored whether dystrophin was affected in an animal model of LCOS. We further investigated whether poloxamer 188 (P188) therapy, found to rapidly ameliorate cardiac dysfunction in a mouse model of abnormal dystrophin, ${ }^{16}$ may be beneficial in this setting.

P188 is a nonionic surfactant with a plethora of purported properties and actions when administered. Its main proposed effects fall into two groups. First, hemorheologic effects-it has been used to improve viscosity, reduce intravascular coagulation, and improve small vessel blood flow in the setting of coronary artery surgery and sickle cell anemia. ${ }^{17,18} \mathrm{He}$ modilution in the setting of pediatric cardiac surgery has been shown to be associated with worsening of cardiac performance, and it has been postulated that reduced hemodilution optimized microcirculatory flows and improved outcomes after surgery. ${ }^{4}$ Given the potential hemorheologic effects of P188, we explored whether it affected the occurrence of hemodilution in this setting. The second group of properties of P188 are its membrane repair effects-it has been used in models of electrocution, myocardial ischemia, and myocardial membrane fragility. ${ }^{16,19,20}$ We considered that it was a reasonable therapy given its myriad of potential beneficial effects in the setting of CPB and its safety profile in human studies. ${ }^{17,18,20}$

Dysferlin, another important membrane-associated protein within the myocardium, has largely been overlooked.
It has been shown to be critical to membrane integrity through membrane repair, and its loss contributes to increased cell permeability. ${ }^{21}$ The loss of both dystrophin and dysferlin creates a membrane that is readily injured, as shown with increased permeability to Evans blue dye. ${ }^{8}$ The role of dysferlin in the setting of CPB is unknown, and we sought to investigate its response to $\mathrm{CPB}$ with $\mathrm{I} / \mathrm{R}$ and whether its expression altered with P188.

Concurrently, we furthered previous investigations into the response of myocardial water channels, in particular AQP1, in the setting of LCOS. $\mathrm{We}^{3}$ have previously shown increased AQP1 transcript after 3 hours' reperfusion and sought to examine protein levels over a longer time frame.

\section{MATERIALS AND METHODS}

The Animal Ethics Committee at The Children's Hospital at Westmead approved this study, and all animals received humane care in compliance with National Health and Medical Research Council animal care guidelines. ${ }^{22}$

\section{Study Design}

Eight lambs of either sex weighing $20.3 \pm 1.7 \mathrm{~kg}$ were used. Three lambs received placebo (CPB-P188) and 5 received $\mathrm{P} 188$ (CPB $+\mathrm{P} 188)$.

Lambs received a blinded solution $(2 \mathrm{~mL} / \mathrm{kg})$ as a bolus load over 1 hour before CPB and then an infusion $\left(0.2 \mathrm{ml} \cdot \mathrm{kg}^{-1} \cdot \mathrm{h}^{-1}\right)$ of the same solution for the remainder of the experiment, 11 hours. Administration was through the central line via an opaque extension (Codan Medlon, Inc, Santa Ana, Calif) and a dedicated syringe driver (Graseby 3200; Graseby Medical, Watford, United Kingdom). The solution was prepared immediately before the experiment. It was filtered via a $0.22-\mu \mathrm{m}$ filter unit (Millipore Co, Cork, Ireland) and wrapped in foil. Phosphate-buffered saline (PBS) was the carrier solution administered without P188 to placebo animals. In treatment animals, P188, also called Pluronic F-68 (Sigma Chemical Co, St Louis, Mo), was added to give a concentration of $150 \mathrm{mg} / \mathrm{mL}$ in PBS, as per previous reports. ${ }^{17}$ Staff involved in animal experiments were unaware of the animal allocation until all data had been analyzed.

In earlier experiments, ${ }^{3} 3$ lambs were anesthetized, received no $\mathrm{PBS} \pm \mathrm{P} 188$, proceeded similarly to sternotomy, and were humanely killed before $\mathrm{CPB}$, for non-CPB data (non-CPB controls).

Experimental preparation. Lambs were anesthetized by spontaneously breathing isoflurane and given intravenous ketamine $(1 \mathrm{mg} / \mathrm{kg})$ and midazolam $(100 \mu \mathrm{g} / \mathrm{kg})$. The lambs were intubated with a $5.5-\mathrm{mm}$ cuffed endotracheal tube. Ventilation and invasive monitoring techniques were relatively standard and identical to that previously described. ${ }^{3} \mathrm{Ve}-$ nous and arterial blood gases were measured regularly. Baseline full blood count, coagulation, liver function, urea, creatinine, and creatinine kinase were measured before CPB. These tests were repeated 6 hours after CPB

CPB technique. Within an hour of intubation, midline sternotomy was performed and the pericardium was opened. CPB was established after heparin administration $(400 \mathrm{IU} / \mathrm{kg}$ ) with right atrial and ascending aorta cannulation. The extracorporeal circuit and prime used were relatively standard and identical to those previously described. ${ }^{3}$ Cardioplegia was repeated every 20 minutes for 120 minutes, at which point the animal was weaned from $\mathrm{CPB}$ and native circulation was re-established. Modified ultrafiltration was performed on all, and internal defibrillation $(0.5-1.0 \mathrm{~J} / \mathrm{kg})$ and/or lidocaine $(1 \mathrm{mg} / \mathrm{kg})$ administered as required.

Postoperative management. After the re-establishment of the circulation, protamine $(1-3 \mathrm{mg} / \mathrm{kg}$ ) was given and hemostasis achieved The sternotomy was closed over two $28 \mathrm{~F}$ intrathoracic drains, which were placed on low-pressure wall suction. Dopamine $\left(5 \mu \mathrm{g} \cdot \mathrm{kg}^{-1} \cdot \mathrm{min}^{-1}\right)$ and 
TABLE 1. Various measurements before and after CPB

\begin{tabular}{|c|c|c|c|}
\hline & & Mean & SEM) \\
\hline & & Before CPB & After CPB \\
\hline Total CK (40-240 IU) & $9 \mathrm{~h}$ & $223(44)$ & $2092(1388$ \\
\hline & $9 \mathrm{~h}+\mathrm{P} 188$ & $204(67)$ & $1781(415)$ \\
\hline & $P$ value & .5 & .5 \\
\hline Dopamine & $9 \mathrm{~h}$ & & $5.2(0.2)$ \\
\hline$\left(\mu \mathrm{g} \cdot \mathrm{kg}^{-1} \cdot \min ^{-1}\right)$ & $9 \mathrm{~h}+\mathrm{P} 188$ & & $4.8(0.5)$ \\
\hline & $P$ value & & .4 \\
\hline Sodium nitroprusside & $9 \mathrm{~h}$ & & $1(0)$ \\
\hline$\left(\mu \mathrm{g} \cdot \mathrm{kg}^{-1} \cdot \min ^{-1}\right)$ & $9 \mathrm{~h}+\mathrm{P} 188$ & & $1.1(0.1)$ \\
\hline & $P$ value & & 1 \\
\hline Input (crystalloid) (mL) & $9 \mathrm{~h}$ & $767(145)$ & $1080(205)$ \\
\hline & $9 \mathrm{~h}+\mathrm{P} 188$ & $808(105)$ & $1052(225)$ \\
\hline & $P$ value & 1 & 1 \\
\hline Input (colloid) (mL) & $9 \mathrm{~h}$ & & $477(46)$ \\
\hline & $9 \mathrm{~h}+\mathrm{P} 188$ & & $554(57)$ \\
\hline & $P$ value & & .4 \\
\hline Input (total) (mL) & $9 \mathrm{~h}$ & & 1557 (197) \\
\hline & $9 \mathrm{~h}+\mathrm{P} 188$ & & $1606(211)$ \\
\hline & $P$ value & & .9 \\
\hline Chest drain loss (mL) & $9 \mathrm{~h}$ & & $667(133)$ \\
\hline & $9 \mathrm{~h}+\mathrm{P} 188$ & & $420(68)$ \\
\hline & $P$ value & & .13 \\
\hline Platelets $\times 10^{9} / \mathrm{L}$ & $9 \mathrm{~h}$ & $315(46)$ & 249 (24) \\
\hline & $9 \mathrm{~h}+\mathrm{P} 188$ & $382(12)$ & $255(61)$ \\
\hline & $P$ value & .16 & .45 \\
\hline APTT (23-34 s) & $9 \mathrm{~h}$ & $33.8(5)$ & $36.9(6)$ \\
\hline & $9 \mathrm{~h}+\mathrm{P} 188$ & $35(3)$ & $40.2(5)$ \\
\hline & $P$ value & .7 & .5 \\
\hline Fibrinogen (1.5-6 g/L) & $9 \mathrm{~h}$ & $2.5(0.5)$ & $2.2(0.3)$ \\
\hline & $9 \mathrm{~h}+\mathrm{P} 188$ & $2.3(0.3)$ & $2.3(0.1)$ \\
\hline & $P$ value & .7 & .5 \\
\hline Mean ACT (on CPB) & $9 \mathrm{~h}$ & $560(80)$ & \\
\hline & $9 \mathrm{~h}+\mathrm{P} 188$ & $622(39)$ & \\
\hline & $P$ value & .7 & \\
\hline
\end{tabular}

$\overline{S E M}$, Standard error of the mean; $C P B$, cardiopulmonary bypass; $C K$, creatinine kinase; $A P T T$, activated partial thromboplastin time; $A C T$, activated clotting time; $P$ value, Mann-Whitney $U$ test.

sodium nitroprusside $\left(1 \mu \mathrm{g} \cdot \mathrm{kg}^{-1} \cdot \mathrm{min}^{-1}\right)$ were commenced after $\mathrm{CPB}$ and kept at these rates. A mean blood pressure greater than $50 \mathrm{~mm} \mathrm{Hg}$ was sought, with crystalloid or maternal blood given to maintain an adequate preload (central venous pressure) greater than $4 \mathrm{~mm} \mathrm{Hg}$ and hemoglobin (hemoglobin $>8 \mathrm{~g} / \mathrm{dL}$ ). Inhalational anesthesia was adjusted according to blood pressure and was supplemented with intermittent intravenous agents (ketamine and midazolam) and pancuronium. Ventilation was maintained and adjusted according to blood gas parameters. All animals were managed by a pediatric intensive care consultant (J.R.E.) using conventional techniques relevant to the care of human infants. Seven hours after completion of CPB, $0.2 \mathrm{mg} / \mathrm{kg}$ of $0.1 \%$ Evans blue dye was given intravenously. ${ }^{23}$

Tissue collection. Nine hours after CPB, the sternotomy was reopened and a dose of pentobarbitone was delivered. After electrical and cardiac standstill, the heart was removed and placed on ice while being dissected for further analysis. The heart was transversely sectioned into atria, great vessels, and ventricles. The ventricles were sectioned for wet/dry weights and together with other organ tissues were either frozen at $-80^{\circ} \mathrm{C}$ or placed in $4 \%$ paraformaldehyde for histologic processing.

\section{Tissue Analysis}

Myocardial water content. Samples of intraventricular septum and left and right ventricular free walls were weighed after blotting. They were dried at $-80^{\circ} \mathrm{C}$ for 48 hours or until their weight was static. Myocardial water content was calculated by ([Wt (wet) - Wt (dry)]/[Wt (wet)]) and expressed as a proportion. ${ }^{24}$ Staining of the myocardium with Evans blue dye was assessed (blinded to allocation) by reviewing five $100 \times$ fields and staining rated as abundant (2), present (1), or absent (0).

Myocardial AQPs. Protein for Western analysis was prepared as previously described ${ }^{25}$ using whole cell lysates from frozen tissue. Membranes were blocked and then incubated with the following primary antibodies, AQP1 (AQP11-A, 1:1000; Alpha Diagnostics, San Antonio, Tex), cardiac/ skeletal actin (5c5 1:3000; Sigma-Aldrich, St Louis, Mo). Total RNA was extracted from tissues using Tri Reagent (Molecular Research Center, Cincinnati, Ohio) followed by cDNA synthesis using random primers $\mathrm{pd}(\mathrm{N})_{6}$ (Roche, Mannheim, Germany) and reverse transcriptase (Superscript III; Invitrogen, Carlsbad, Calif). Quantitative reverse transcriptase-polymerase chain reaction was performed with LUX primers (Invitrogen) as previously described. ${ }^{3}$ All samples were run in duplicate and experiments performed in triplicate. AQP levels were quantified during 45 cycles with a Rotor-Gene RG 3000A (Corbett Research, Mortlake, NSW, Australia), and analysis was performed with Rotor-Gene Real Time Analysis Version 6.0 (Corbett Research, 2004). AQP mRNA levels were normalized to 18 S rRNA.

Myocardial dystrophin and dysferlin. Total protein for Western analysis was prepared as previously described. ${ }^{25}$ Membrane and myocellular preparations were prepared according to the published method of Kido and associates ${ }^{14}$ after ultracentrifugation and then run as previously described. ${ }^{25}$ Membranes were probed with the following primary antibodies for dystrophin: MANDRA-1 (1:250) (Sigma-Aldrich) for the C terminus, Dys1 (1:200) (Novocastra, Newcastle, United Kingdom) for the rod domain, and Dys3 (1:20) (Novocastra) for the N-terminus, with appropriate positive and negative controls. ${ }^{12,14,15}$ Dysferlin was detected with the antibody Hamlet1 (1:200) (Novocastra). Loading was controlled with an antibody to $\alpha$-actinin-2 (1:200,000).

\section{Statistical Analysis}

Data were expressed as means \pm SEM. Statistical significance was determined by both the Mann-Whitney $U$ test and linear mixed models using covariance type AR-1. The statistical package SPSS version 15.0 for Windows (SPSS, Inc, Chicago, Ill) was used for analysis. The animals with or without P188 were compared in terms of hemodynamic variables-both functional and biochemical. Hemodynamic data variables were analyzed over the complete survival period and also by comparison of 60-minute epochs. Our sample size gave us $80 \%$ power to demonstrate that a 0.7 standard deviation effect size difference between groups was significant at a $P$ value of $0.05 .{ }^{26}$ For measures of protein expression, myocardial water, and blood tests, comparison was made between control animals and 9-hour post-CPB $\pm \mathrm{P} 188$.

\section{RESULTS}

All experiments were completed as intended. No inotropes or vasodilators were administered before CPB, and rates of administration after CPB were similar (Table 1). There were no significant differences in pre-CPB hemodynamic values, apart from a lower heart rate in the $\mathrm{CPB}+\mathrm{P} 188$ group (Table 2).

\section{Molecular Results}

Dystrophin, measured in membrane fractions, was unchanged in the CPB-P188 group compared with non-CPB controls $(P=.3)$. Membrane dystrophin expression was 
TABLE 2. Hemodynamic and laboratory variables post-CPB

\begin{tabular}{|c|c|c|c|c|c|c|c|c|c|c|}
\hline & \multirow[b]{2}{*}{ Baseline } & \multicolumn{9}{|c|}{ Hours after CPB } \\
\hline & & 1 & 2 & 3 & 4 & 5 & 6 & 7 & 8 & 9 \\
\hline \multicolumn{11}{|l|}{ Mean $( \pm$ SEM $)$} \\
\hline \multicolumn{11}{|l|}{ CVP (mm Hg) } \\
\hline $9 \mathrm{~h}$ & $2.0(0.5)$ & $3.3(0.6)$ & $2.6(0.4)$ & $2.9(0.4)$ & $3.1(0.4)$ & $2.6(0.4)$ & $1.9(0.4)$ & $2.5(0.6)$ & $2.6(0.5)$ & $2.7(0.6)$ \\
\hline $9 \mathrm{~h}+\mathrm{P} 188$ & $2.5(0.5)$ & $4.2(0.6)$ & $3.5(0.5)$ & $2.8(0.4)$ & $2.7(0.4)$ & $2.7(0.4)$ & $2.8(0.4)$ & $2.7(0.4)$ & $2.1(0.5)$ & $2.3(0.4)$ \\
\hline$P$ value* & .5 & .37 & .52 & .17 & .14 & .49 & .91 & .51 & .66 & .75 \\
\hline$P$ value $\dagger$ & & & & & & & & & & .88 \\
\hline \multicolumn{11}{|l|}{ HR (beats/min) } \\
\hline $9 \mathrm{~h}$ & $131(6)$ & $148(4)$ & $153(3)$ & $152(5)$ & $147(3)$ & $157(5)$ & $156(4)$ & $145(3)$ & $135(3)$ & $127(2)$ \\
\hline $9 \mathrm{~h}+\mathrm{P} 188$ & $107(4)$ & 147 (3) & $153(3)$ & $162(3)$ & $163(2)$ & $158(2)$ & $159(3)$ & $161(2)$ & $155(3)$ & $144(3)$ \\
\hline$P$ value* & $<.01$ & .75 & .62 & .2 & $<.01$ & .54 & .64 & $<.01$ & $<.01$ & $<.01$ \\
\hline$P$ value $\dagger$ & & & & & & & & & & .15 \\
\hline \multicolumn{11}{|l|}{$\mathrm{SBP}(\mathrm{mm} \mathrm{Hg})$} \\
\hline $9 \mathrm{~h}$ & $93(5)$ & $94(3)$ & $93(3)$ & $101(3)$ & $101(2)$ & $91(2)$ & $84(1)$ & $79(2)$ & $74(2)$ & $75(2)$ \\
\hline $9 \mathrm{~h}+\mathrm{P} 188$ & 89 (3) & $96(3)$ & $102(2)$ & $102(1)$ & $95(1)$ & $91(2)$ & $95(2)$ & $93(2)$ & $87(2)$ & $84(2)$ \\
\hline$P$ value* & .6 & .47 & .01 & .54 & .02 & .99 & $<.01$ & $<.01$ & $<.01$ & $<.01$ \\
\hline$P$ value $\dagger$ & & & & & & & & & & .12 \\
\hline \multicolumn{11}{|l|}{$\mathrm{MBP}(\mathrm{mm} \mathrm{Hg})$} \\
\hline $9 \mathrm{~h}$ & $75(4)$ & $66(4)$ & $72(3)$ & $76(2)$ & $75(2)$ & $69(2)$ & $62(1)$ & $58(2)$ & $55(1)$ & $56(2)$ \\
\hline $9 \mathrm{~h}+\mathrm{P} 188$ & $74(3)$ & $76(3)$ & $84(2)$ & $81(1)$ & $75(1)$ & $73(2)$ & $75(2)$ & $73(1)$ & $68(2)$ & $65(1)$ \\
\hline$P$ value* & .8 & .04 & $<.01$ & .05 & .97 & .08 & $<.01$ & $<.01$ & $<.01$ & $<.01$ \\
\hline$P$ value $\dagger$ & & & & & & & & & & $<.01$ \\
\hline \multicolumn{11}{|l|}{$\mathrm{DBP}(\mathrm{mm} \mathrm{Hg})$} \\
\hline $9 \mathrm{~h}$ & $62(3)$ & $60(3)$ & $55(3)$ & $58(2)$ & $57(2)$ & $51(1)$ & $46(1)$ & $43(2)$ & $41(1)$ & $43(2)$ \\
\hline $9 \mathrm{~h}+\mathrm{P} 188$ & $62(3)$ & $63(3)$ & $70(1)$ & $63(1)$ & $56(1)$ & $56(2)$ & $58(1)$ & $54(1)$ & $51(1)$ & 49 (1) \\
\hline$P$ value* & .8 & .43 & $<.01$ & .02 & .78 & .03 & $<.01$ & $<.01$ & $<.01$ & $<.01$ \\
\hline$P$ value $\dagger$ & & & & & & & & & & $<.01$ \\
\hline $\mathrm{COP}(\mathrm{mOsm})$ & $\Delta$ from baseline & & & & & & & & & \\
\hline $9 \mathrm{~h}$ & $13.3(0.8)$ & $-2(0.3)$ & & $-1.2(0.2)$ & & & $-1.8(0.5)$ & & & $-3.5(0.5)$ \\
\hline $9 \mathrm{~h}+\mathrm{P} 188$ & $12.6(0.5)$ & $0.4(1.8)$ & & $-0.5(0.8)$ & & & $-1.4(1.4)$ & & & $-1.5(0.6)$ \\
\hline$P$ value* & .30 & .46 & & .37 & & & .55 & & & .02 \\
\hline Hct $(\%)$ & $\Delta$ from baseline & & & & & & & & & \\
\hline $9 \mathrm{~h}$ & $29.4(2.1)$ & $-3.9(2.9)$ & & $-5.0(1.8)$ & & & $-3.2(1.2)$ & & & $-2.9(2.1)$ \\
\hline $9 \mathrm{~h}+\mathrm{P} 188$ & $23.8(1.8)$ & $7.1(2.3)$ & & $5.8(1.4)$ & & & $7.7(1.7)$ & & & $5.6(3.0)$ \\
\hline$P$ value* & .1 & .05 & & .03 & & & .03 & & & .1 \\
\hline $\mathrm{Hb}(\mathrm{g} / \mathrm{dL})$ & $\Delta$ from baseline & & & & & & & & & \\
\hline $9 \mathrm{~h}$ & $9.5(0.7)$ & $-1.3(0.9)$ & & $-1.7(0.6)$ & & & $-1.1(0.4)$ & & & $-1.0(0.7)$ \\
\hline $9 \mathrm{~h}+\mathrm{P} 188$ & $8.0(0.6)$ & $2.0(0.8)$ & & $1.6(0.4)$ & & & $2.2(0.5)$ & & & $2.1(0.7)$ \\
\hline$P$ value* & .18 & .05 & & .03 & & & .03 & & & .05 \\
\hline Venous sat $(\%)$ & $\Delta$ from baseline & & & & & & & & & \\
\hline $9 \mathrm{~h}$ & 92.5 & $-8.5(6.3)$ & & $-0.5(3.4)$ & & & $-6.7(1.5)$ & & & $-9.4(2.5)$ \\
\hline $9 \mathrm{~h}+\mathrm{P} 188$ & 82.8 & $3.8(14.3)$ & & $13.3(7.3)$ & & & $8.6(7.1)$ & & & $9.6(7)$ \\
\hline$P$ value* & .65 & .72 & & .30 & & & .05 & & & .05 \\
\hline Lactate $(\mathrm{mmol} / \mathrm{L})$ & $\Delta$ from baseline & & & & & & & & & \\
\hline $9 \mathrm{~h}$ & $1.23(0.26)$ & $3.83(0.72)$ & & $0.83(0.28)$ & & & $-0.10(0.2)$ & & & $-0.23(0.2)$ \\
\hline $9 \mathrm{~h}+\mathrm{P} 188$ & $2.14(0.42)$ & $1.26(0.67)$ & & $-0.56(0.5)$ & & & $-1.08(0.4)$ & & & $-1.18(0.4)$ \\
\hline$P$ value* & .10 & .04 & & .07 & & & .17 & & & .09 \\
\hline
\end{tabular}

higher in the $\mathrm{CPB}+\mathrm{P} 188$ group (using antibodies to both $\mathrm{C}$ terminus and rod domain) compared with CPB-P188 and non-CPB control groups $(P<.05$, Figure $1, A)$. Antibodies to the N-terminus of the human form of dystrophin did not cross-react with sheep dystrophin.
Dysferlin expression was significantly reduced at the membrane after CPB in the CPB-P188 group compared with nonCPB controls $(P<.05)$. In the $\mathrm{CPB}+\mathrm{P} 188$ group, there was maintenance of dysferlin expression at levels similar to those in the non-CPB control animals $(P=.8$, Figure $1, B)$. 

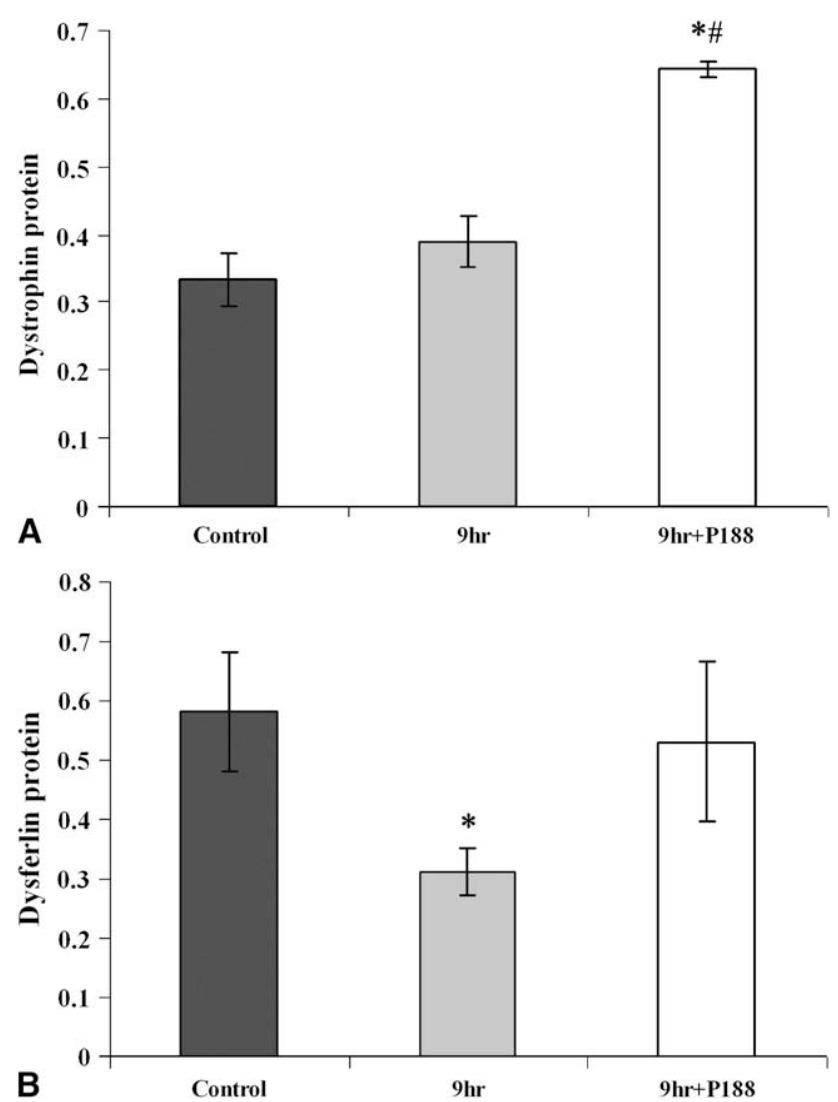

FIGURE 1. Myocardial membrane fraction densitometry. Membrane fractions were measured by Western blot densitometry (controlled for protein loading by $\alpha$ actinin- 2 measurement). Lambs are grouped as non CPB-controls (solid bar), CPB-P188 (gray bar), and CPB $\mathrm{P} 188$ (open bar). Protein levels were compared between groups with the Mann-Whitney $U$ test. A, The $\mathrm{CPB}+\mathrm{P} 188$ group shows higher membrane dystrophin levels than the non-CPB control $(* P<.05)$ and CPB-P188 $(\# P<.05)$, B. The CPB-P188 group shows a significant decrease in dysferlin expression compared with the non-CPB control $\left({ }^{*} P<.05\right)$. $C P B$, Cardiopulmonary bypass.

AQP1 protein levels were increased 9 hours after CPB in the CPB-P188 group compared with non-CPB controls $(P<.05)$. The $\mathrm{CPB}+\mathrm{P} 188$ animals displayed less of a rise in AQP1 protein expression than did non-CPB controls $(P=.28$, Figure 2$)$.

\section{Myocardial Water}

The myocardium of CPB-P188 animals tended to be more edematous $(0.78 \pm 0.005)$ than the hearts of the $\mathrm{CPB}+\mathrm{P} 188$ group $(0.77 \pm 0.003)$, although nonsignificantly $(P=.08)$. Evans blue dye uptake was greater in the CPB-P188 group $(2.6 \pm 0.2)$ than in the $\mathrm{CPB}+\mathrm{P} 188$ group $(1.7 \pm 0.2 ; P<.05)$. Albumin tended to fall by more in the CPB-P188 animals than the $\mathrm{CPB}+\mathrm{P} 188$ group $(3.33 \pm 0.67 \mathrm{~g} / \mathrm{L}$ vs $0.8 \pm$ $1.7 \mathrm{~g} / \mathrm{L})$, although nonsignificantly $(P=.17)$. Colloid osmotic pressure was significantly reduced by $3.5 \pm 0.46$ mOsm in the CPB-P188 animals at 9 hours compared with $1.46 \pm 0.58 \mathrm{~mm} \mathrm{Hg}$ in the $\mathrm{CPB}+\mathrm{P} 188$ animals

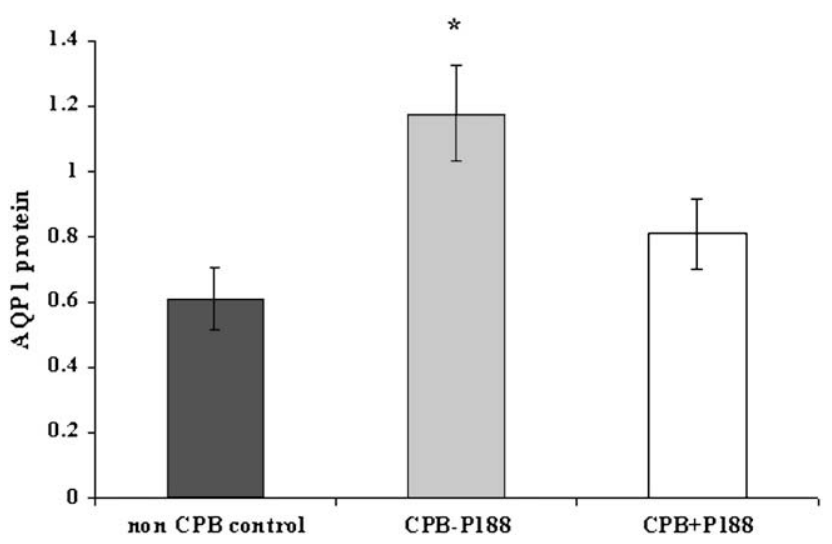

FIGURE 2. Myocardial aquaporin $1(A Q P 1)$ protein expression. Western analysis of total AQP1 protein was normalized to cardiac actin. Lambs are grouped as non-CPB controls (solid bar), CPB-P188 (gray bar), and $\mathrm{CPB}+\mathrm{P} 188$ (open bar). Protein levels were compared between groups with the Mann-Whitney $U$ test. Representative results demonstrate a significant increase at 9 hours after $\mathrm{CPB}$ in the CPB-P188 group compared with non-CPB controls $(* P<.05)$. $C P B$, Cardiopulmonary bypass.

$(P<.05)$ (Figure 3 and Table 2). There were no significant differences in volumes of crystalloid or colloid fluid administered (Table 1). There was a trend toward greater chest drain losses in the CPB-P188 group $(P=.13$, Table 1$)$.

\section{Biochemistry and Hematology}

Creatinine increased in the CPB-P188 group by 10.7 $\pm 4.4 \mu \mathrm{mol} / \mathrm{L}$, compared with a reduction in the $\mathrm{CPB}+\mathrm{P} 188$ animals of $11 \pm 6.9 \mu \mathrm{mol} / \mathrm{L}(P<.05)$. Urea tended to increase not significantly in the $\mathrm{CPB}-\mathrm{P} 188$ group $1.78 \pm$ $0.49 \mathrm{mmol} / \mathrm{L}$, whereas in the $\mathrm{CPB}+\mathrm{P} 188$ animals it rose by $0.72 \pm 0.67 \mathrm{mmol} / \mathrm{L}(P=.18)$. Total creatinine kinase did not differ significantly between groups (Table 1 ). The CPB-P188 group initially had a higher lactate after reperfusion than did the CPB $+\mathrm{P} 188$ animals $(P<.05$, Figure $4, E$, and Table 2). Venous saturation was increased from baseline in those receiving P188 at 6 and 9 hours after CPB $(P=.05$, Figure $4, F$, and Table 2$) . \mathrm{P} 188$ was associated with a maintenance of hemoglobin and hematocrit compared with baseline (Figure 3 and Table 2). There were no significant differences in other hematology and coagulation tests (Table 1).

\section{Hemodynamics}

Heart rate and systolic blood pressure tended to be lower in the CPB-P188 animals in the later epochs $(P<.01$ at $7-9$ hours after $\mathrm{CPB})$ but overall were not different $(P=.15$ and $P=.12$, respectively) (Figure $4, A$ and $B$, and Table 2). The CPB-P188 animals had significantly lower mean blood pressure and diastolic blood pressure throughout the 9hour period after CPB $(P<.01)$ (Figure $4, C$ and $D$, and Table 2). Central venous pressure was similar overall between groups $(P=.88$, Table 2$)$. 


\section{DISCUSSION}

A clinically accurate animal model of reduced myocardial performance was studied. Previously undescribed changes in altered expression of proteins within the myocardial membrane were found. Hallmarks of reduced performance, such as lower blood pressure and lower oxygen delivery, were lessened in association with the administration of the membrane protecting P188. P188 treatment was also associated with potentially beneficial changes in membrane protein expression, reduced capillary leakage, and reduced hemodilution. However, this was a small study and consequently its findings can at best suggest avenues for further analysis. Our use of clinically relevant surgical, perfusion, and anesthetic techniques provided a clinically valid model of the milder spectrum of LCOS.

Dystrophin is a candidate protein in the contractile failure that occurs in the setting of LCOS and has not been previously investigated in that context. Regional ischemia brought about by coronary occlusion in animals has been shown to reduce both its membrane location and overall expression. ${ }^{14,15}$ Ischemic cardiomyopathy has also been associated with reduced dystrophin expression, but examination with a specific $\mathrm{N}$-terminus antibody was necessary. ${ }^{12}$ In several ways, regional ischemia and end-stage ventricular failure represent more severe forms of disease than that experienced with present-day infant heart surgery. In our clinical model of LCOS, we found no change in dystrophin after CPB with I/R. Evidence from others suggests it is possible that changes occurred only at the N-terminus, which we were not able to study with the antibodies available for sheep. However, we consider this unlikely, given that we observed increases in dystrophin expression associated with P188 therapy that were identical with both the rod domain and C-terminus antibodies. CPB with I/R represent a planned insult, and current myocardial protection techniques appear adequate in preventing an acute dystrophinopathy occurring in this setting.

Dysferlin has been shown to have a specific and critical role in membrane injury in animal models of both skeletal and cardiac muscle, ${ }^{8,21}$ but its response to CPB and $\mathrm{I} / \mathrm{R}$ has not previously been determined. Membrane dysferlin protein expression was significantly reduced after $\mathrm{CPB}$ and I/R in our study. Dysferlin loss was associated with evidence of increased membrane damage and a greater reduction in colloid osmotic pressure. Available studies suggest dysferlin-mediated membrane repair is indispensable for the maintenance of cellular integrity in models of muscle stress. $^{8}$ Thus, the reduction in dysferlin associated with $\mathrm{CPB}$ and $\mathrm{I} / \mathrm{R}$ may represent an important aspect of the pathophysiology contributing to LCOS.

LCOS in this study was mild and characterized by lower blood pressure and impaired oxygen delivery. Lactate was raised after CPB whereas venous saturations and blood pressure were reduced after $\mathrm{CPB}$ in the control group. Post-CPB venous saturations, blood pressure, and lactate were im-

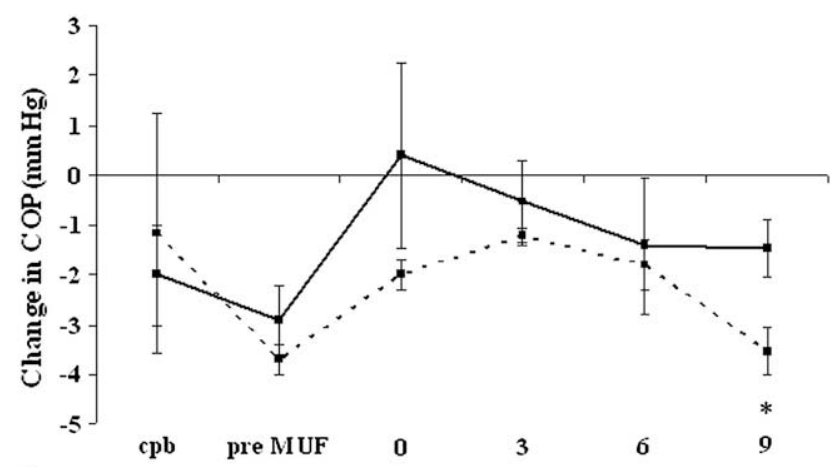

A Time post $\mathrm{cpb}(\mathrm{h})$

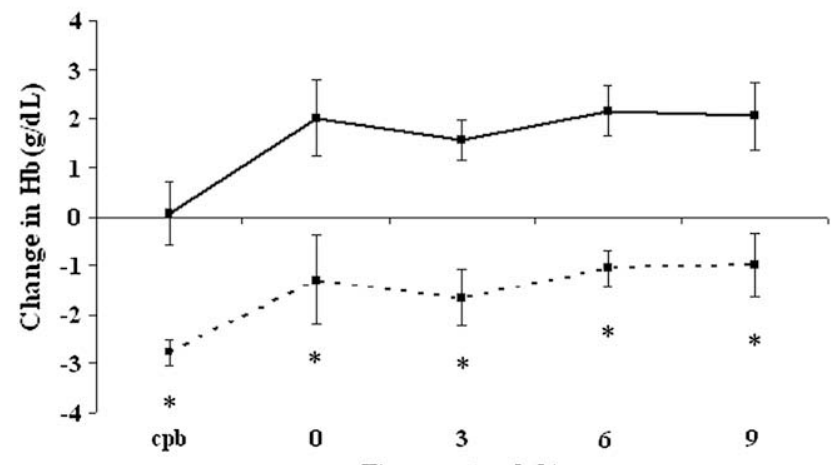

B

Time post cpb(h)

FIGURE 3. Measures of colloid osmotic pressure and hemoglobin. Lambs are grouped as CPB-P188 (dashed line) and CPB $\mathrm{P} 188$ (solid line). Comparison between groups was by the Mann-Whitney $U$ test. A, Reduction in colloid osmotic pressure was greater at 9 hours in the CPB-P188 group 3.5 $\pm 0.46 \mathrm{~mm} \mathrm{Hg}$ compared with a drop of $1.46 \pm 0.58 \mathrm{~mm} \mathrm{Hg}$ in the $\mathrm{CPB}+\mathrm{P} 188$ animals $\left({ }^{*} P<.05\right)$. B, Hemoglobin dropped in the CPB-P188 group after $\mathrm{CPB}$ compared with the $\mathrm{CPB}+\mathrm{P} 188$ animals $(* P<.05) . C P B$, Cardiopulmonary bypass; $C O P$, colloid osmotic pressure; $H b$, hemoglobin; $M U F$, modified ultrafiltration.

proved in association with P188. Hemoglobin was preserved after CPB in association with P188 administration, and this is likely to have partly contributed to improved oxygen delivery and hemodynamics in this group. Large studies have shown an association between reduced hemodilution and improved outcome. Interestingly, Jonas and colleagues ${ }^{4}$ in the Boston Hemodilution Study also reported an initially raised lactate after CPB in the more hemodiluted group. The control animals in our study had a drop in hemoglobin on CPB, and after $\mathrm{CPB}$ they were more hemodiluted than the $\mathrm{CPB}+\mathrm{P} 188$ animals. These control animals also had an initially raised lactate after CPB. This pattern of hemodilution was also seen in our previous animal experiments. ${ }^{3}$ In the $\mathrm{P} 188$ group of animals, however, there was a stable hemoglobin on CPB and the lactate was not as elevated as in the control group after $\mathrm{CPB}$. This rise in hemoglobin was maintained throughout the postoperative period. Given that there were no substantive differences in coagulation, the P188 may be responsible for minimizing red cell loss and minimizing hemodilution through reducing membrane injury. 

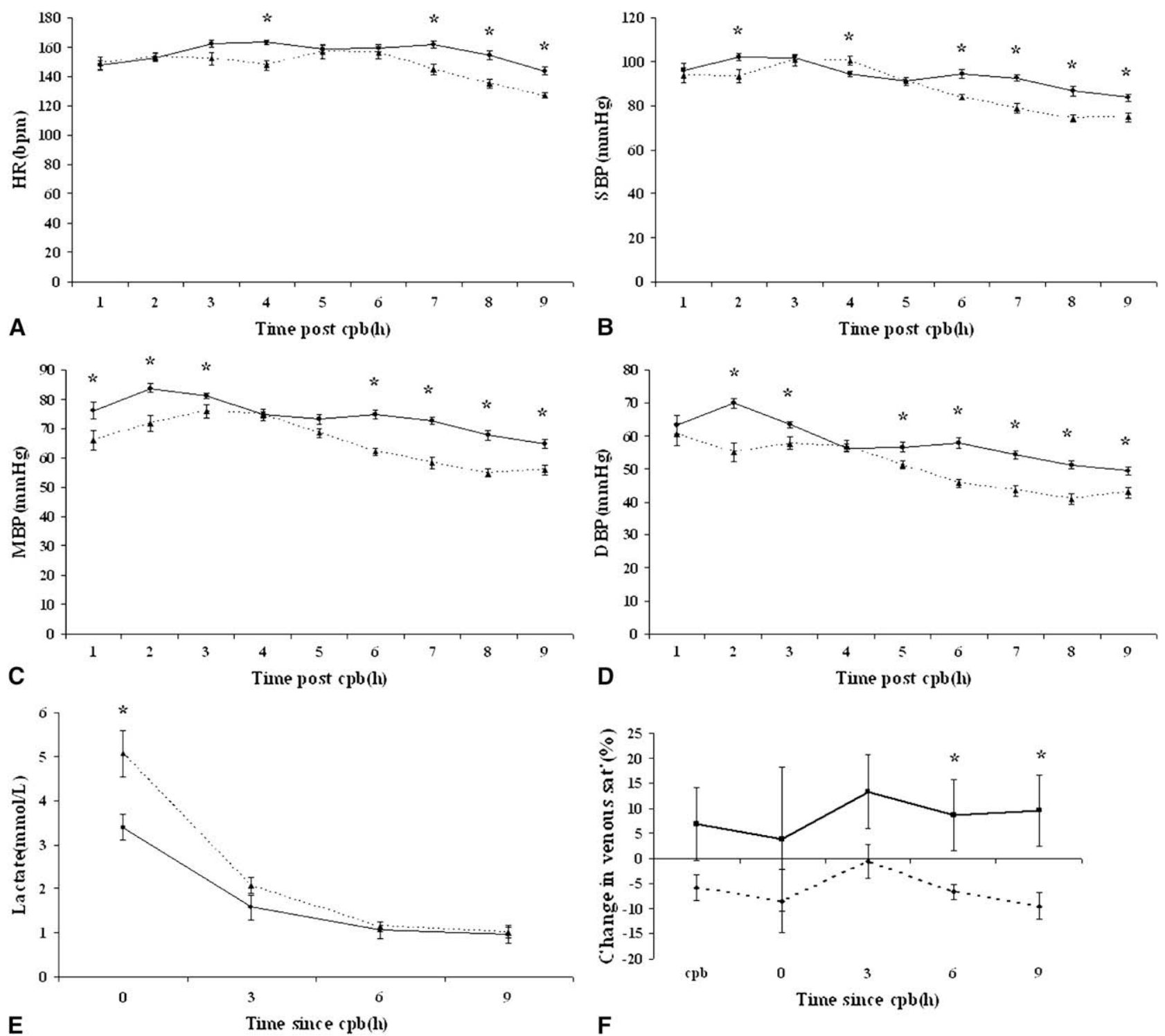

FIGURE 4. Hemodynamic and biochemical variables. Lambs are grouped as CPB-P188 (dashed line) and CPB+P188 (solid line). Comparison between groups was by both the Mann-Whitney $U$ test and linear mixed models using covariance type AR-1 as appropriate. A, Heart rate $(H R)$ was higher in the $\mathrm{CPB}+\mathrm{P} 188$ group during the later epochs, but overall the difference was not significant. B, Systolic blood pressure (SBP) was significantly higher in the $\mathrm{CPB}+\mathrm{P} 188$ group during the later epochs, but overall not different, $\mathrm{C}$ and $\mathrm{D}$, Mean blood pressure $(M B P)$ and diastolic blood pressure $(D B P)$, respectively. Both are significantly higher overall in the $\mathrm{CPB}+\mathrm{P} 188$ group $\left({ }^{*} P<.01\right)$. E, Lower lactate in the $\mathrm{CPB}+\mathrm{P} 188$ group after reperfusion $(* P<.05)$, but similar levels subsequently. $\mathrm{F}$, The change in venous saturation after $\mathrm{CPB}$ compared with baseline was significantly higher in the CPB+P188 group at 6 and 9 hours after $\mathrm{CPB}$, with a final increase of $10 \% \pm 7 \%$ compared with a drop in the CPB-P188 group of $9 \% \pm 3 \%(* P=.05)$.

Animals in the control group had unaltered dystrophin, reduced dysferlin expression, and increased membrane damage. P188 has been shown by others to rapidly correct abnormalities in dystrophin, ${ }^{16}$ although in the post-cardiac surgery setting an acute dystrophinopathy was not apparent in our study. Interestingly, P188 therapy was associated with an increase in membrane dystrophin to supranormal levels. Increased membrane dystrophin has been shown to occur in response to ischemic preconditioning in an animal model, suggesting that increased expression of dystrophin may have beneficial functional effects. ${ }^{14}$ The role of this increase in dystrophin expression cannot at this stage be linked to the apparent improvements seen with this treatment.

It has been suggested that P188 would also be beneficial in the setting of abnormalities in dystrophin-related proteins such as dysferlin. ${ }^{16} \mathrm{P} 188$ administration before $\mathrm{CPB}$ and $\mathrm{I} / \mathrm{R}$ was associated with maintenance of normal dysferlin levels. Maintenance of dysferlin levels has been shown in other settings to be associated with less membrane injury. ${ }^{8}$ There was evidence of less membrane injury in the animals receiving 
P188, and these animals also had higher levels of dysferlin expression. Hence, dysferlin warrants further study in this post-CPB setting.

P188 may have other hemodynamic effects. The prophylactic use of P188 has shown benefit in improving blood viscosity in a small trial of coronary bypass surgery. ${ }^{18} \mathrm{It}$ was also shown to have benefits on neurologic outcome after deep hypothermic cardiac arrest in a large animal model of CPB. ${ }^{27}$ Despite these benefits in planned ischemia, it was not beneficial in a large trial as adjunctive therapy after acute myocardial infarction. ${ }^{20}$ There were also no beneficial effects on infarct size or hemodynamics, and safety concerns arose with increased creatinine levels. It is possible that benefits associated with P188 were obscured by patient heterogeneity and the failure of P188 to treat, rather than prevent, ischemia-related injury. In our study, the use of modified ultrafiltration with CPB may have removed excess P188 and perhaps minimized any renal injury. We did not demonstrate a rise in creatinine associated with P188; in fact, creatinine was reduced in those animals. We found a maintenance of hemoglobin levels and no coagulopathy associated with its use. P188 may also have reduced red blood cell fragility.

The role of edema and water transport proteins in the setting of LCOS has not been established. We have previously demonstrated that AQP1 mRNA increased 2-fold in the setting of LCOS after CPB with I/R, but we did not observe an associated rise in AQP1 protein at 3 hours. ${ }^{3}$ After a longer period ( 9 hours) of observation, both AQP1 mRNA and protein were increased 2-fold. While a 2-fold increase is modest, the associated changes in capillary leak suggest that AQP1 may have a role in capillary leak. The fact that P188 was also associated with a normalization of raised AQP1 protein levels and reduced markers of capillary leak provides further support. To determine whether this change in AQP1 expression is a pathologic or beneficial compensatory response will require direct modulation of the channel. Increased AQP1 expression could be part of the explanation for the transudate that occurs into the tissues of the body after CPB and I/R. ${ }^{28}$

This study was limited by its small size and by the fact that it was conducted in animals. The animals also did not have structural heart disease and hence no preoperative hypertrophy as a result of volume or pressure loading. A range of clinically relevant refinements such as inotropes, vasodilators, cardioplegia, and modified ultrafiltration were used to improve the clinical validity of the model. These therapies are likely to have reduced the underlying severity of LCOS and may have had other effects, but because of their place in current clinical practice, they were included. The hemodynamic and functional monitoring used to support our findings were simple, but equivalent and relevant to techniques relied on in the clinical setting. All animals were managed in the post-CPB period by one individual in the same way with a view to maintaining critical parameters within acceptable limits. This best reflects clinical practice but added a potentially confounding variable in assessing outcomes; blinding to therapy should effectively have minimized any impact from this variable. The molecular changes that occurred in dysferlin and AQP proteins are novel and warrant further investigation. Load-independent measurements of systolic and diastolic function would be beneficial in future studies to completely define a functional benefit related to P188. Although we have not sought to define the mechanistic action of P188 in this study, we have generated data to support further study of P188 in this setting.

We thank Professor Jenny Peat, statistician, for her advice on study design and data analysis. Dr Nan Yang provided assistance with the molecular analysis and interpretation. Dr Pramesh Kovoor and Jim Pouliopoulos provided assistance with perfusion and monitoring. Dr Susan Arbuckle and Aysen Yuksel provided histopathology assistance. Leanne Mills and Trish McGregor assisted with logistics.

\section{References}

1. Hoffman TM, Wernovsky G, Atz AM, Kulik TJ, Nelson DP, Chang AC, et al. Efficacy and safety of milrinone in preventing low cardiac output syndrome in infants and children after corrective surgery for congenital heart disease. Circulation. 2003;107:996-1002.

2. Bolli R, Marban E. Molecular and cellular mechanisms of myocardial stunning. Physiol Rev. 1999;79:609-34.

3. Egan JR, Butler TL, Cole AD, Aharonyan A, Baines D, Street N, et al. Myocardia ischemia is more important than the effects of cardiopulmonary bypass on myocardial water handling and postoperative dysfunction: a pediatric animal model. J Thorac Cardiovasc Surg. 2008;136:1265-73.e2.

4. Jonas RA, Wypij D, Roth SJ, Bellinger DC, Visconti KJ, du Plessis AJ, et al. The influence of hemodilution on outcome after hypothermic cardiopulmonary bypass: results of a randomized trial in infants. J Thorac Cardiovasc Surg. 2003; 126:1765-74.

5. Stocker CF, Shekerdemian LS, Norgaard MA, Brizard CP, Mynard JP, Horton SB, et al. Mechanisms of a reduced cardiac output and the effects of milrinone and levosimendan in a model of infant cardiopulmonary bypass. Crit Care Med. 2007;35:252-9.

6. Caldarone CA, Barner EW, Wang L, Karimi M, Mascio CE, Hammel JM, et al Apoptosis-related mitochondrial dysfunction in the early postoperative neonatal lamb heart. Ann Thorac Surg. 2004;78:948-55.

7. McNally EM, MacLeod H. Therapy insight: cardiovascular complications associated with muscular dystrophies. Nat Clin Pract Cardiovasc Med. 2005;2:301-8.

8. Han R, Bansal D, Miyake K, Muniz VP, Weiss RM, McNeil PL, et al. Dysferlinmediated membrane repair protects the heart from stress-induced left ventricular injury. J Clin Invest. 2007;117:1805-13.

9. Au CG, Cooper ST, Lo HP, Compton AG, Yang N, Wintour EM, et al. Expression of aquaporin 1 in human cardiac and skeletal muscle. J Mol Cell Cardiol. 2004; 36:655-62.

10. Manley GT, Fujimura M, Ma T, Noshita N, Filiz F, Bollen AW, et al. Aquaporin-4 deletion in mice reduces brain edema after acute water intoxication and ischemic stroke. Nat Med. 2000;6:159-63.

11. Goodwin FC, Muntoni F. Cardiac involvement in muscular dystrophies: molecular mechanisms. Muscle Nerve. 2005;32:577-88.

12. Vatta M, Stetson SJ, Perez-Verdia A, Entman ML, Noon GP, Torre-Amione G, et al Molecular remodelling of dystrophin in patients with end-stage cardiomyopathies and reversal in patients on assistance-device therapy. Lancet. 2002;359:936-41.

13. Lee YT, Sung K, Shin JO, Jeon ES. Images in cardiovascular medicine. Disruption of dystrophin in acute fulminant coxsackieviral B4 infection. Circulation. 2006;113:e76-7.

14. Kido M, Otani H, Kyoi S, Sumida T, Fujiwara H, Okada T, et al. Ischemic preconditioning-mediated restoration of membrane dystrophin during reperfusion correlates with protection against contraction-induced myocardial injury. Am J Physiol Heart Circ Physiol. 2004;287:H81-90. 
15. Rodriguez M, Cai WJ, Kostin S, Lucchesi BR, Schaper J. Ischemia depletes dystrophin and inhibits protein synthesis in the canine heart: mechanisms of myocardial ischemic injury. J Mol Cell Cardiol. 2005;38:723-33.

16. Yasuda S, Townsend D, Michele DE, Favre EG, Day SM, Metzger JM. Dystrophic heart failure blocked by membrane sealant poloxamer. Nature. 2005;436: 1025-9.

17. Adams-Graves P, Kedar A, Koshy M, Steinberg M, Veith R, Ward D, et al. RheothRx (poloxamer 188) injection for the acute painful episode of sickle cell disease: a pilot study. Blood. 1997;90:2041-6.

18. Hunter RL, Papadea C, Gallagher CJ, Finlayson DC, Check IJ. Increased whole blood viscosity during coronary artery bypass surgery. Studies to evaluate the effects of soluble fibrin and poloxamer 188. Thromb Haemost. 1990;63:6-12.

19. Lee RC, Hannig J, Matthews KL, Myerov A, Chen CT. Pharmaceutical therapies for sealing of permeabilized cell membranes in electrical injuries. Ann N Y Acad Sci. 1999;888:266-73.

20. Effects of RheothRx on mortality, morbidity, left ventricular function, and infarct size in patients with acute myocardial infarction. Collaborative Organization for RheothRx Evaluation (CORE). Circulation. 1997;96:192-201.

21. Bansal D, Miyake K, Vogel SS, Groh S, Chen CC, Williamson R, et al. Defective membrane repair in dysferlin-deficient muscular dystrophy. Nature. 2003;423: 168-72.
22. NHMRC. Australian code of practice for the care and use of animals for scientific purposes. 7th ed; 2004.

23. Zhang S, Wang S, Li Q, Yao S, Zeng B, Ziegelstein RC, et al. Capillary leak syndrome in children with C4A-deficiency undergoing cardiac surgery with cardiopulmonary bypass: a double-blind, randomised controlled study. Lancet. 2005; 366:556-62.

24. Jia CX, Rabkin DG, Hart JP, Dean DA, Cabreriza SA, Weinberg AD, et al. Regional variation in myocardial water content in the edematous pig heart. $J$ Surg Res. 2002;106:70-5.

25. Butler TL, Au CG, Yang B, Egan JR, Tan YM, Hardeman EC, et al. Cardiac aquaporin expression in humans, rats, and mice. Am J Physiol Heart Circ Physiol. 2006;291:H705-13.

26. Kusuoka H, Hoffman JI. Advice on statistical analysis for Circulation Research. Circ Res. 2002;91:662-71.

27. Mezrow CK, Mazzoni M, Wolfe D, Shiang HH, Litwak RS, Griepp RB. Poloxamer 188 improves neurologic outcome after hypothermic circulatory arrest. J Thorac Cardiovasc Surg. 1992;103:1143-6.

28. Farstad M, Heltne JK, Rynning SE, Onarheim H, Mongstad A, Eliassen F, et al. Can the use of methylprednisolone, vitamin $\mathrm{C}$, or alpha-trinositol prevent coldinduced fluid extravasation during cardiopulmonary bypass in piglets? J Thorac Cardiovasc Surg. 2004;127:525-34. 